\title{
Spiritual diagnostic criteria in an African setting: The case of baruti in Limpopo province, South Africa
}

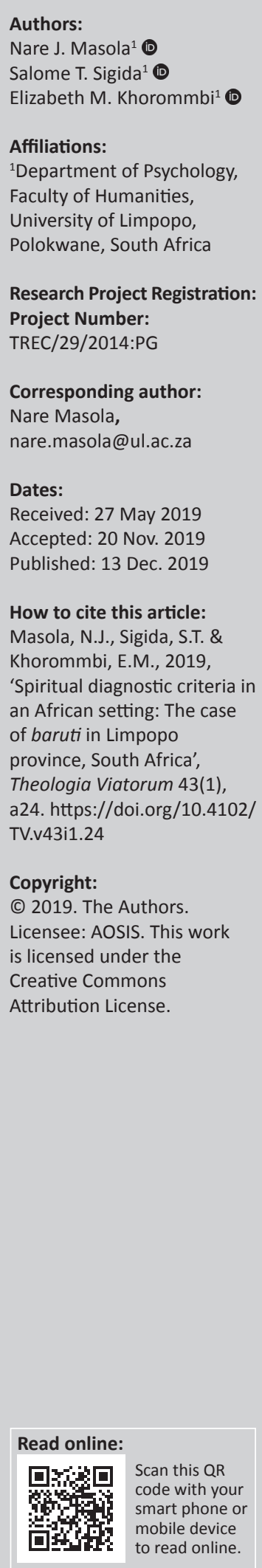

In many provinces of South Africa, especially in the indigenous societies, baruti (pastors) are consulted for different purposes, paramount among them being the execution of good health. The research was carried out to explore the diagnostic measures used to diagnose chronic diseases by pastors in Limpopo, South Africa. Ten pastors who specialised in chronic diseases were interviewed through individual semi-structured interviews in the Ga-Dikgale rural community, and the data were analysed using a thematic content analysis. The findings of the study indicate that diagnosis of chronic diseases by the participants relied primarily on power confession, and discernment of spirits. The researcher concludes by recommending policymakers and Western-trained health care practitioners to acknowledge the pastors as experts in their own right, as an additional resource in health promotion in the rural communities.

Keywords: pastor; South Africa; discernment; health promotion; diagnosis.

\section{Introduction}

The consultation of prophets and pastors for the diagnosis of various diseases is not a new practice in Africa. Biomedical diagnostic tools, such as Diagnostic and Statistical Manual of Mental Disorders IV (DSM IV), mammography, psychological assessment tests and physiological tests, are available in both Western and African societies. However, the biomedical system operates alongside a multitude of other healing practices in many societies, such as faith practice, traditional practice, spiritual practice, et cetera. Undeniably, in many low- and middle-income countries, there are various categories of alternative healers who form a large part of the health care system (Mkhwanazi 2016:193). Given the accessibility of alternative healers, the local people utilise the complementary medicine practitioners to understand what informed the causes of illnesses (Tlou 2013:272).

In parts of Africa, especially in South African rural communities, some diseases are believed to be the result of the influence of supernatural forces, which may include sorcery, witchcraft, spirit disturbance and breaching of taboos or breaking kinship rules or religious obligation (Edwards 2011:335). As indicated by Azongo and Abdulai (2014:999), these beliefs are usually embedded in religions, which tend to influence individual world views. Subsequently, in some societies, especially in South Africa, the consultation of prophets and pastors for diagnosis of chronic diseases is arguably because of the cultural beliefs, values, norms and folklore shared by the healers and the patients. To a large extent, these shared beliefs about chronic diseases determine the help-seeking behaviours of chronically ill people in the rural communities in Africa. In addition to these belief systems, these beliefs also contain questions about the effectiveness of biomedical diagnostic tools in the diagnosis of these chronic diseases that are believed to have emanated from cultural elements (Sodi \& Bojuwoye 2011:349).

It is however important to note that every human society has its own cultural and knowledge systems for explaining and diagnosing chronic diseases (Bojuwoye \& Sodi 2010:283; Sodi \& Bojuwoye 2011:349). This indicates that the different ways in which people conceptualise the social and natural environments reflect their basic assumption about, and view of, the universe that gives orientation and value to their lives. From another perspective, world view represents the source of explanation for the ways things are in the world, including theories of illness, death and misfortune, and how human afflictions and difficulties are approached and managed (Moshabela, Zuma \& Gaede 2016:83).

This paper assesses the Spiritual Diagnostic Criteria in an African setting. The focus on this aspect is of paramount importance because it has not been fully explored by scholars in the field of 
religion or other related fields. Furthermore, of particular importance is the location of the study, Ga-Dikgale - a typical African community. As such, it is important to note that in view of the diversities in human orientation across societies and cultures, thoughts, reasoning and ways of knowing of people within these societies also differ in many ways, especially from the dominant Western thought and reasoning (Yidana 2014). Therefore, it is imperative to note that conclusions about health, well-being and the possible interventions during illness episodes are often managed in accordance with the people's belief structures (Mkhwanazi 2016:201). Hence, this article aims to contribute towards the knowledge system of the diagnostic tools used by the pastors in the rural communities in the Limpopo province. Conversely, the researcher was guided by an Afrocentric perspective to chronic diseases (Asante 2003).

\section{Theology and religion}

Beyers (2017) is of the opinion that the position and status that religion enjoys in society in recent times has changed. The argument is that values and religious viewpoints that were previously accepted without question, are now being questioned. In some cases, they are attacked or ridiculed. In many instances, religious communities need to resort to a confrontational path in order to retain formerly unquestioned positions or rights. Religious leaders who had the ear of the authorities a couple of decades ago have since then found that their influence has been reduced to the size of the community they represent (Beyers 2017). It has also been noted that Christians increasingly experience challenges from people of other faiths such as Judaism and Islam. In such situations, it is imperative that they are aware of their own position as well as that of the other parties.

\section{Contextualising spirituality and health}

One vital reflection around Africans is the fact that they are infamously spiritual. Depending on which religion one is aligned with, the individual religious philosophies invade into all aspects of their lives so fully that, it is not easy to separate religion from their daily activities (Nwoye 2011:304). This conviction presumes that religion plays a key role in people's understanding of any phenomenon, including disease and ill-health (Azongo \& Abdulai, 2014: 999). It is further worth noting that a usual indigenous South African view of the cause of any given disease stems mostly from the individual cosmology or world view. As a consequence, ailments where causes are not known are often attributed to supernatural forces. This attribution, however, can only be understood through supernatural means (Laher 2014:191). This way of life is sustained because many people are socialised into these cosmologies and as such, any enlightenment provided for disease causation has to reflect these cosmologies to make it meaningful. It should not only reflect the cosmology but must be conventional to all parties, that is patient, affected people and practitioners (Mokgobi 2014:24).

\section{Diagnosticians procedures from an African perspective}

In African societies, some traditional healers act in their capacity as a diviner-diagnostician, or diviner-medium, whereas some traditional healers act as herbalists (Neba 2011:139). Diviners are experts at smearing diagnostic criteria (Mpofu 2006:375, 2011). As such, diviners not only define the disease but also identify its origin and context, from the perspective of the African belief systems (Semenya, Potgieter \& Erasmus 2012:440). Moreover, diviners identify the origin and context, which enable them to prescribe an appropriate plant- or animal-based treatment through spiritual means (Mpofu 2006:375, 2011).

Diagnostic procedures common among most indigenous healers across the world involve repetitive rituals that comprise complex social negotiations and interactions (Moagi 2009:116). Within the religious systems, diagnosis is believed to be undertaken under the guidance of spiritual forces, and diseases are often attributed to the influence of Satan or the Jinn, or are considered as punishment from God (Ross 2010:44). Furthermore, the expressions used to describe a religious/cultural diagnosis will depend largely on the culture or religion that the diagnosis applies to. For example, in Islam, it is common to hear of a Jinn possession, whereas in the Christian faith, the term evil spirit possession is mostly used (Laher 2014:191).

\section{The concept of moruti (pastor) in the South African context}

Despite the study findings that attempt to explain the categories of indigenous healers, the differences between a faith healer, traditional healer and indigenous healer are not clearly articulated. However, a pastor in this article is contextualised in accordance with the pastor's description of the role of moruti/pastor in the Limpopo province. A pastor in Ga-Dikgale, the Limpopo province, is believed to be a person who heals mostly through prayer, laying hands on patients or providing holy water and ash. They believe that their healing power comes from God through ecstatic states and trance contact with a spirit (moya), or sometimes a combination of both, the Christian Holy Spirit and the ancestral spirit. In addition, some pastors use a combination of herbs, remedies and holy water in their treatment depending on the church affiliation. Their healing system is moulded on the sangoma group pattern, whereby the afflicted live for months and sometimes years at the pastor's residence. It has been noted that the general tradition of healing by pastors includes laying hands on the sick individual (Laher 2014:191). Holistic expression of healing defines healing as a multi-dimensional component that has different facets to it (Sodi 2011:214). Therefore, pastors heal only physical illness, which means healing is multi-faceted. In addition, the vigorous display of emotions in rhythmic movements and dances, which are common practice in pastors' churches, follows the same patterns as the ceremonial dances of the sangomas (Masola 2016:20). 


\section{The craft of consulting the baruti}

An imperative observation about the baruti with regard to their consultation and what helps them in the detection of the unknown is that all the pastors who were interviewed generally used very similar items for their craft (Azongo \& Abdulai 2014:999). Thus, the common aspects that were used by these pastors are the Holy Spirit, prayer and musical instruments. Yet, still others relied on holy water, anointed cloth and anointing oil to uncover the unknown (Nwoye 2011:306). During a church service, it is believed that the Holy Spirit speaks to the pastor or points to the objects or makes certain signs that are interpreted by the pastor (Nwoye 2011:304).

\section{Methodology Research design}

The study used a qualitative research methodology and, in particular, an exploratory research design (Babbie \& Mouton 2011). According to Francis (2011), exploratory studies are small-sample designer used primary for gaining insights and ideas about the illnesses. Hence, the exploratory design was deemed suitable for the present study, as it sought to gain insights on the diagnostic method of healing chronic diseases by a faith healer.

\section{Study sample and setting}

Ten male Sepedi-speaking pastors, aged between 20 and 65 years, were selected from various villages around the GaDikgale community in Limpopo province through snowball sampling (Babbie 2015). Participant educational qualifications were as follows: Diploma $(n=3)$, junior degrees $(n=3)$ and postgraduate degrees $(n=4)$. Compared with most rural people living in the communities, the pastors were relatively well educated. The majority of the participants (50\%) were head pastors with $30 \%$ being senior pastors, whilst the remaining $20 \%$ classified themselves as pastors.

The research site for the study was the rural community of Ga-Dikgale that falls under the Capricorn District in the Limpopo province. Ga-Dikgale is situated about $40 \mathrm{~km}-45$ $\mathrm{km}$ northeast of Polokwane, which is the capital city of the Limpopo province. The community is governed by a Kgoši (traditional leader). All villages in Ga-Dikgale have the same communal grazing land some distance away from a residential area. Settlements in Ga-Dikgale are a mixture of traditional mud huts, conventional brick houses and shacks, with an estimated total population of $7900-8000$ people. A considerable number of community members in this area belong to Christian churches (e.g. faith mission churches, Zion Christian churches and Apostolic churches) that are headed by bishops, prophets, head pastors and pastors.

\section{Data collection}

Informed consent was obtained from the participants before the study was conducted. Anonymity and confidentiality were ensured throughout the study.
Data on diagnostic methods used to diagnose chronic diseases were collected by means of in-depth, semistructured, face-to-face interviews that were conducted using a pre-prepared interview guide. The participants were interviewed in their homes and churches. The data were audio-taped and later transcribed by the researchers. The transcripts were double-checked by an independent researcher who is Sepedi-speaking and has experience in qualitative research. After the transcripts were doublechecked, they were translated into English by an independent English expert before the data could be analysed. To ensure the trustworthiness of the research findings, the researchers involved peer researchers to assist with interpretation and analysis of the data. Furthermore, the findings, interpretations and implications of the study were interrogated by the researchers a few times to ensure that they were supported by data.

\section{Data analysis}

The transcribed and translated data were analysed using the thematic content analysis method following the guidelines suggested by Kvale (1983:171). The process consists of reading through textual data, identifying themes in the data, coding those themes and then interpreting the structure and content of the themes. The Nvivo computer software version 10 was used to classify, sort and arrange the information so that analysis and interpretation could take place.

\section{Ethical consideration}

The study received ethical clearance from the University of Limpopo's Research Ethics Committee (TREC Number: TREC/29/2014:PG). Permission to access the research site and to conduct the study was granted by the Dikgale traditional authority in Limpopo province where the study was conducted. Informed consent was obtained from the participants before the study was conducted. Anonymity and confidentiality were ensured throughout the study.

\section{Findings}

From the findings of the study, the following themes emerged: discernment of spirits and power of confession.

\section{Discernment of spirits}

Discernment was perceived by most of the participants $(n=8)$ to be the most common method to identify chronic diseases, as many of them believed that they do not have the competence to diagnose these morbid conditions. Most participants believed that they are guided by the Holy Spirit to discern chronic diseases. The following extracts depict the perceived method given by participants:

\footnotetext{
'... It comes as a prophecy ....' (Participant \# 5, male, 42 years old)

'... One of the gifts of the spirit we have discernment, word of knowledge and word of wisdom ....' (Participant \# 3, male, 49 years old)
} 


\section{Power of confession}

The findings suggest that some participants $(n=4)$ strongly believe in the power of confession, as evidenced in the following extracts:
... We cannot say we having techniques to diagnose, diagnose is for people who are from school, who are trained doctors ....' (Participant \# 4, male, 62 years old)
'... You just look at the symptoms, certain symptoms ... we don't have any detection that we can diagnose.' (Participant \# 6, male, 42 years old)
'... We get explanation from the person.' (Participant \# 7, male, 38 years old)

\section{Implications of the findings}

Based on the findings from the study, it appears that the participants believe that they have the ability to discern chronic diseases through contacts with the spiritual world. However, they refer matters that are clinical to the allopathic practitioners, because the participants perceive themselves as operating at the spiritual level. This implies that the participants are fully aware of the limitations of their work when it comes to medical conditions like chronic diseases. In this regard, they suggest a room for themselves and the health professionals when diagnosing the chronic diseases of their congregants.

\section{Discussion}

Findings from the current study revealed that pastors' diagnostic mechanisms are contrasted with the mechanisms followed by the Western approaches. The Western perspective views chronic diseases to be fundamentally biological in origin, and which can best be diagnosed with the use of biomedical diagnostic tools. This corresponds with the findings by World Health Organization (2013), indicating that medical practitioners are able to more accurately diagnose chronic diseases and develop superior solutions to these chronic diseases. In addition, in studies conducted by Chan (2008:4-9) and Mkhwanazi (2016:193), it was argued that biomedical approaches tend to focus more readily on the symptoms of diseases and the location of the body.

Findings of the present study revealed that the participants are fully aware of their limitations when it comes to the diagnosis of chronic conditions. However, they believe that they have the ability to discern chronic diseases through their dealings with the spiritual world. In other words, the participants appear to refer matters that are clinical to the medical experts, whilst they perceive themselves to be operating primarily at the spiritual level. The findings lend support to the views of Truter (2007:56) and Mokgobi (2014:24) who state that faith healers (including pastors) are usually professed Christians of African faith-based churches or mission independent churches and operate in the spiritual realm. The findings further correspond with those of Sodi and Bojuwoye (2011:349) who postulated that faith healers are called by the Holy Spirit or ancestral spirits, and diagnosis and treatment is done using the Bible and prayers usually using the laying on of hands.

It is revealed from the findings of this study that the participants do seem to suggest a room for themselves and the health professionals to collaborate in managing the conditions of their congregants. This is consistent with the Traditional Health Practitioners Bill in South Africa, No. 25 of 2007, which made attempts at the 'formalisation, regulation, and professionalisation' of traditional health care system in South Africa (Zuma et al. 2016:12906). However, in view of the developments, which include legislation to officially recognise the role of THPs, it becomes imperative to understand the role that this alternative health care system can play in health promotion in South Africa. This will be with a view towards collaboration between traditional health practitioners and Westernoriented health practitioners (Street 2016:22).

\section{Implications of the theory}

In the present study, the research was guided by an Afrocentric perspective to chronic diseases. The Afrocentric perspective examines topics from the perspective of the African people as subjects of historical experiences (Asante 2003). Therefore, in order to understand the African perspective on chronic and other forms of diseases, it is important to have an understanding of the African concepts of the causes of diseases as well as how different forms of diseases are diagnosed and treated (Bojuwoye \& Sodi 2010:283).

Consistent with the Afrocentric approach, it is evident that most of the participants in the present study emphasised the importance of culture in their causal explanations of chronic diseases, including the way they diagnose and treat these conditions. For example, the results indicate that participants seemed to explain chronic diseases to be incurable, but to be healed through divine interventions, as they are believed to be mostly caused by cultural and spiritual factors. Furthermore, the participants used their own understanding and knowledge that was influenced by their spiritual context and their sociocultural perceptions of the chronic diseases.

\section{Limitations and recommendations}

One of the limitations of the present study relates to the small sample that was obtained through snowball sampling. Consequently, the results of the present study cannot be generalised to the larger South African population. Future studies based on larger samples should be conducted to understand the role of the different types of healers (e.g. pastors, prophets, bishops, traditional faith healers, and so forth) in the management of chronic diseases. The study further recommends that policymakers and Western-trained health care practitioners need to treat faith healers as experts in their own right and as an additional resource for health promotion in communities. 


\section{Acknowledgements}

The authors would like to thank God because without him they would not have had the strength and courage throughout the years; they know they would not have made it this far. They would also like to thank Prof. Tholene Sodi, for his guidance and support in this research project, and Vlaamse Interuniversitaire Raad-Institutional University Cooperation (VLIR-IUC) Partnership Programme - for the inclusion of this study in their bigger research project and for the financial support provided during the study. They also thank Dr J.R. Rammala for editing the manuscript and the faith healers from Ga-Dikgale for their willingness to participate in the study.

\section{Competing interests}

The authors have declared that no competing interests exist.

\section{Authors' contributions}

All authors contributed equally to this work.

\section{Funding information}

Appreciation is extended to the authors' colleagues from within the Department of Psychology, University of Limpopo, for their support in ensuring that the analysis represents a fair account of the narrative data collected. This reflection represents learning from research activities supported by the Flemish University Council-University Development Cooperation (VLIR-UOS). Any opinion, finding and conclusion or recommendation expressed in this article are that of the authors and VLIR-UOS does not accept any liability in this regard.

\section{Data availability statement}

Data are available and analysed using thematic content analysis.

\section{Disclaimer}

The views and opinions expressed in this article are those of the authors and do not necessarily reflect the official policy or position of any affiliated agency of the authors or the funders.

\section{References}

Asante, M.K., 2003, Afrocentricity: The theory of social change, African American Images, Chicago, IL.

Azongo, B.T. \& Abdulai, A., 2014, 'Complementary or contradictory? Role of diviners in health care delivery in Ghana: Implications and consequences', International Journal of Research in Health Sciences 2(4), 999-1008.

Babbie, E.R., 2015, The practice of social research, Nelson Education, Boston, MA.

Babbie, E.R. \& Mouton, J., 2011, The practice of social research, Oxford University Press, Cape Town.
Beyers, J., 2017, 'A historical overview of the study of theology of religions', HTS Theological Studies/Teologiese Studies suppl. 12, 73(6), a4837. https://doi. org/10.4102/hts.v73i6.4880

Bojuwoye, O. \& Sodi, T., 2010, 'Challenges and opportunities to integrating traditional healing into counselling and psychotherapy', Counselling Psychology Quarterly 21(3), 283-296. https://doi.org/10.1080/09515070.2010.505750

Chan, M., 2008, 'The first World Health Organization Congress on traditional medicine: Psychology in society', Journal of Psychology 26(1), 4-9.

Edwards, S.D., 2011, 'A psychology of indigenous healing in South Africa', Journal of Psychology in Africa 21(3), 335-348. https://doi.org/10.1080/14330237.2011.10 820466

Francis, C.D., 2011, Evaluating research methodology for people need to read research, Sage, London.

Kvale, S., 1983, 'The qualitative research interview: A phenomenological and hermeneutical mode of understanding', Journal of Phenomenological Psychology 14(2), 171-195. https://doi.org/10.1163/156916283X00090

Laher, S., 2014, 'An overview of illness conceptualizations in African, Hindu and Islamic traditions: Towards cultural competence', South African Journal of Psychology 44, 191-204. https://doi.org/10.1177/0081246314528149

Masola, N.J., 2016, Conceptualization and treatment of chronic diseases by faith healers at Ga-Dikgale community, Limpopo Province, University of Limpopo, Mankweng.

Mkhwanazi, N., 2016, 'Medical anthropology in Africa: The trouble with a single story', Medical Anthropology 35(2), 193-202. https://doi.org/10.1080/01459740.2015. 1100612

Moagi, L., 2009, 'Transformation of the South African care system with regards to African healers: The social effects of inclusion and regulation', International NGO Journal 4(4), 116-126.

Mokgobi, M., 2014, 'Understanding traditional African healing', African Journal for Physical Health Education, Recreation and Dance 20(2), 24-34.

Moshabela, M., Zuma, T. \& Gaede, B., 2016, 'Bridging the gap between biomedical and traditional health practitioners in South Africa', South African Health Review 20(16), 83-92.

Mpofu, E., 2006, 'Majority world health care traditions intersect indigenous and complementary and alternative medicine'. International Journal of Disability, Development and Education 5(3), 375-380. https://doi.org/10.1080/10349120 601008340

Mpofu, E., 2011, Counselling people of African ancestry, Cambridge University Press, Cambridge.

Neba, N.E., 2011, 'Traditional health care system and challenges in developing ethnopharmacology in Africa: Example of Oku, Cameroon', Ethno Medicine 5(2), 133-139. https://doi.org/10.1080/09735070.2011.11886400

Nwoye, A., 2011, 'Igbo cultural and religious worldview: An insider's perspective', International Journal of and Anthropology 3(9), 304-317.

Ross, E., 2010, 'Inaugural lecture: African spirituality, ethics and traditional healingImplications for indigenous South African social work education and practice' South African Journal of Bioethics \& Law 3(1), 44-51.

Semenya, S., Potgieter, M.J. \& Erasmus, L., 2012, 'Ethnobotanical survey of medicinal plants used by Bapedi healers to treat diabetes mellitus in the Limpopo Province, South Africa', Journal of Ethnopharmacology 14(1), 440-445. https://doi. org/10.1016/j.jep.2012.03.008

Sodi, T., 2011, 'Indigenous healers' diagnostic and treatment methods of illness and social dysfunctions', Indilinga: African Journal of Indigenous Knowledge Systems 8(1), 60-73. https://doi.org/10.4314/indilinga.v8i1.48243

Sodi, T. \& Bojuwoye, O., 2011, 'Cultural embeddedness of health, illness and healing: Prospects for integrating indigenous and Western healing practices', Journal of Psychology in Africa 21(3), 349-356. https://doi.org/10.1080/14330237.2011.10 820467

Street, R.A., 2016, 'Unpacking the new proposed regulations for South African traditional 822 health practitioners', South African Medical Journal 106(4), 22-23. https://doi.org/10.7196/SAMJ.2016.v106i4.10623

Tlou, E.R., 2013, 'A South African perspective on culturally congruent mental health services', Journal of Black Psychology 3(9), 272-275. https://doi.org/10.1177/ 0095798413480659

Truter, I., 2007, 'Complementary and alternative medicine African traditional healers: Cultural and religious beliefs intertwined in a holistic way', South African Pharmaceutical Journal 74(8), 56-60.

World Health Organization, 2013, Traditional medicine strategy 2014-2023, World Health Organization, Geneva.

Yidana, A., 2014, 'Socio-religious factors influencing the increasing plausibility of faith healing in Ghana', Doctoral thesis, Martin Luther University.

Zuma, T., Wight, D., Rochat, T. \& Moshabela, M., 2016, 'The role of traditional health practitioners in rural KwaZulu-Natal, South Africa: Generic or mode-specific?', BMC Complementary and Alternative Medicine 16, 1-13. https://doi.org/10.1186/ s12906-016-1293-8 